\title{
Análise farmacognóstica das folhas de Arrabidaea chica (Humb. \& Bonpl.) B. Verlt., Bignoniaceae
}

\author{
Mauro Sérgio Marques Alves, ${ }^{1}$ Patrizia Cardoso Mendes, ${ }^{5}$ Janaína Gell de Pontes Vieira, ${ }^{2}$ \\ Eliana Ferreira Ozela, ${ }^{3}$ Wagner Luiz Ramos Barbosa, ${ }^{4}$ José Otávio Carréra Silva Júnior ${ }^{*, 5}$
}

\author{
${ }^{1}$ Programa de Pós-graduação em Ciências Farmacêuticas, Faculdade de Farmácia, Universidade Federal do Pará, \\ Cidade Universitária Professor José da Silveira Neto, 66075-900 Belém-PA, Brasil \\ ${ }^{2}$ Laboratório de Botânica, Instituto de Ciências Biológicas, Universidade Federal do Pará, Cidade Universitária \\ Professor José da Silveira Neto, 66075-900 Belém-PA, Brasil \\ ${ }^{3}$ Laboratório de Bromatologia, Faculdade de Farmácia, Universidade Federal do Pará, Cidade Universitária \\ Professor José da Silveira Neto, 66075-900 Belém-PA, Brasil \\ ${ }^{4}$ Laboratório de Fitoquímica, Faculdade de Farmácia, Universidade Federal do Pará, \\ Cidade Universitária Professor José da Silveira Neto, 66075-900 Belém-PA, Brasil, \\ ${ }^{5}$ Laboratório de Farmacotécnica, Faculdade de Farmácia, Universidade Federal do Pará, Cidade Universitária \\ Professor José da Silveira Neto, 66075-900 Belém-PA, Brasil.
}

\begin{abstract}
RESUMO: Arrabidaea chica (Humb. \& Bonpl.) B. Verlt. é uma Bignoniaceae amplamente utilizada na medicina popular como anti-inflamatório e adstringente, e para várias doenças como cólicas intestinais, diarréias, anemias e enfermidades da pele. Devido as suas propriedades biológicas e a produção de corante a espécie passou a ser utilizada pela indústria cosmética. A utilização de produtos naturais de origem vegetal implica no controle de qualidade farmacobotânico e em ensaios de pureza que compõem as especificações técnicas da espécie. Para isso foi realizada a descrição anatômica das folhas jovens e maduras de A. chica a partir de observações realizadas ao microscópio óptico, a partir de cortes histológicos. As folhas são hipoestomáticas e dorsiventrais com mesofilo heterogêneo. No pecíolo, a epiderme é uniestratificada contendo tricomas e dotada de cutícula delgada. Os testes farmacopéicos incluíram a determinação da distribuição granulométrica do pó da planta, determinação do teor de umidade e de cinzas totais, além da abordagem fitoquímica da tintura, visando estabelecer parâmetros para seu controle de qualidade.
\end{abstract}

Unitermos: Arrabidaea chica, Bignoniaceae, plantas medicinais, farmacobotânica, controle de qualidade.

\begin{abstract}
Pharmacognostic analysis of Arrabidaea chica (Humb. \& Bonpl.) B. Verlt. Leaves, Bignoniaceae”. Arrabidaea chica (Humb. \& Bonpl.) B. Verlt. is a Bignoniaceae widely used in the popular medicine as anti-inflammatory and astringent agent, and for some illnesses as intestinal colic, diarrhoeas, anaemia and diseases of the skin. Its biological properties and dye biosynthesis lead the species to be used in the cosmetic industry. The use of natural products of vegetal origin implies in pharmacognostic quality control and purity assays that compose the technical specifications of the material. Therefore, the anatomical description of mature and young leaves of A. chica was carried through the use of optic microscopy on histological preparations. The leaves are hipostomatic and dorsiventral with heterogeneous mesophile. In petiole, the epidermis is unistratified, it contains trachoma and it is endowed with thin cuticle. The pharmacopoeia assays included the determination of the grain size distribution of the plant drug, the determination of humidity and the total ashes, beyond the phytochemistry approach of tincture, to establish parameters for its quality control.
\end{abstract}

Keywords: Arrabidaea chica, Bignoniaceae, medicinal plants, pharmacognosy, quality control.

\section{INTRODUÇÃO}

Os recursos da flora vêm sendo utilizados pelo homem no tratamento de diversas patologias. Há relatos, por exemplo, do uso de plantas com finalidades terapêuticas que datam de 3.000 a.C. (Tyler, 1996; Ko, 1999).

Foi através da observação e da experimentação pelos povos primitivos que as propriedades terapêuticas de determinadas plantas foram sendo descobertas e propagadas de geração em geração, fazendo parte da 
cultura popular (Turolla \& Nascimento, 2006).

No Brasil plantas medicinais são comercializadas em feiras livres e mercados populares, além daquelas cultivadas nos quintais residenciais. No Mercado do Vero-Peso, em Belém-PA, são comercializadas cerca de 1.200 plantas dentre elas a Arrabidaea chica (H\&B) Verlt., Bignoniaceae, mais conhecida pela população paraense pelo nome de pariri, (Amoroso \& Gely, 1988) (Figuras $1 \mathrm{e}$ 2).

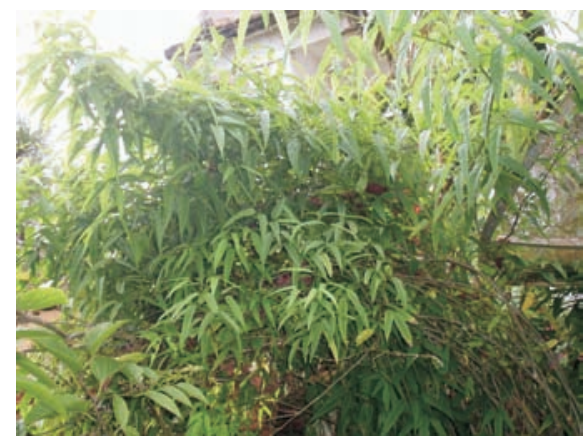

Figura 1. Aspecto geral de Arrabidaea chica (H\&B) Verlt., cultivada em jardim residencial na cidade de Belém-PA. (Fotografia do autor).

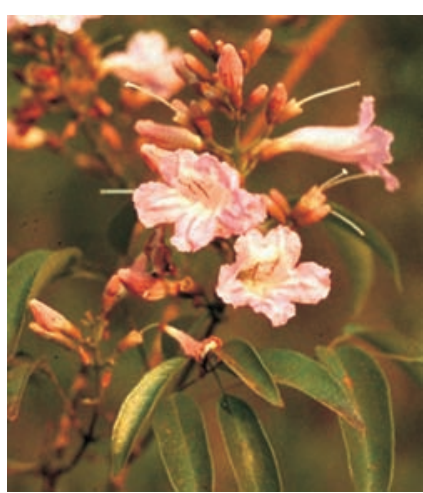

Figura 2. Floração da Arrabidaea chica (H\&B)Verlt. (www. plantamed.com.br)

A espécie A. chica recebe ainda várias denominações nas diversas regiões brasileiras tais como cipó-pau, cipó-cruz, carajuru, carapiranga, carajiru, crajiru, carajeru, crejer, entre outras (Corrêa, 1984). A espécie pertence à família Bignoniaceae, a qual encerra 120 gêneros com aproximadamente 800 espécies que são encontradas na sua maioria, em regiões tropicais e subtropicais, com dois grandes centros de distribuição geográfica, o Brasil e o Continente Africano. Observa-se que o Brasil é, provavelmente, a região onde a família apresenta-se com o maior número de espécies, ocorrendo desde a Amazônia até o Rio Grande do Sul, não possuindo um habitat único (Pauletti et al., 2003).

$\mathrm{Na}$ espécie foram identificados vários pigmentos como a bixina, genipina e derivados da cajurina, que produzindo um corante vermelho-escuro servem para tingir uma variedade de fibras artesanais, sendo supostamente eficazes contra dermatoses e impingens (Corrêa,1984). O corante é utilizado pelos indígenas da região Amazônica na pintura corporal, para tingir enfeites, utensílios e vestuários, na arte, magia e até como método profilático contra picada de mosquitos. Estudos químicos relatam o isolamento de fitosteróis, flavonoides e pigmentos utilizados em cosméticos como: carajurona, carajurina e 3-deoxiantocianidina (Estrela, 1995). As propriedades tintoriais da espécie são devidas a dois pigmentos flavônicos: a carajurina, que é o pigmento principal e a carajurona (Grenard, 1987).

As folhas da espécie são utilizadas popularmente na forma de chás para o tratamento de cólicas intestinais, diarréias, anemias, inflamações uterinas, hemorragias, leucemia, icterícia, albuminúria, impingens, micoses e lavagem de ferimentos na pele (Corrêa, 1984). Devido à propriedade adstringente do extrato das folhas, este é utilizado na cosmética em forma de sabonete cremoso produzindo um efeito anti-acne (Takemura, 1995) e antifúngico (Barbosa \& Quignard, 1998).

O objetivo deste trabalho foi realizar estudos farmacognósticos das folhas de Arrabidaea chica (Humb. \& Bonpl.) B. Verlt. tais como: descrição anatômica, determinação do teor de umidade e de cinzas totais, além da determinação da distribuição granulométrica do pó da planta e abordagem fitoquímica da tintura, visando estabelecer parâmetros para o seu controle de qualidade, obedecendo ao estabelecido na Resolução da Diretoria Colegiada (RDC) n 48, de 16 de março de 2004 (Anvisa, 2004).

\section{MATERIAL E MÉTODOS}

\section{Coleta e identificação botânica}

O material vegetal, Arrabidaea chica (H\&B) Verlt., Bignoniaceae, foi obtido junto à Associação dos Vendedores de Ervas do Mercado do Ver-o-Peso (Associação Ver-as-Ervas), procedente da região metropolitana de Belém-PA, distrito de Icoaraci, coletado em janeiro de 2007 e posteriormente identificado no herbário do Museu Paraense Emílio Goeldi, em exsicata sob n ${ }^{\circ}$ MG 1050701 e MG 123919.

Uma parte do material botânico foi preparada para as análises macroscópicas e anatômicas, outra parte foi dessecada a $40{ }^{\circ} \mathrm{C}$, triturada e o pó assim obtido foi utilizado nos demais ensaios.

\section{Estudos anatômicos}

Os estudos microscópios foram realizados com material fixado em glutaraldeído $2,5 \%$, em tampão fosfato de sódio $0,1 \mathrm{M}(\mathrm{pH} 7,2)$ e desidratado em série gradual etílica crescente para infiltração em hidroxietilmetacrilato. 
As secções foram feitas em micrótomo de rotação modelo Jung para a confecção das lâminas permanentes. O material foi corado com fucsina básica $1 \%$ e azul de Astra, observado em microscópio óptico e fotomicrografado em fotomicroscópico Medlux, modelo XSZ-150Ai.

\section{Secagem e moagem}

As folhas jovens e maduras, após higienização foram dessecadas em estufa a $40{ }^{\circ} \mathrm{C}$. Após secagem, o material foi triturado até a forma de pó em moinho de faca de aço inoxidável modelo Tecnel TCL-650.

\section{Determinação da distribuição granulométrica do pó}

Foi baseada no que preconiza a Farmacopéia Brasileira (1988), onde exatamente $10 \mathrm{~g}$ da planta seca pulverizada foram submetidos à série de tamizes com abertura de malha $(2,36$ e $1,40 \mathrm{~mm} ; 850,710,600,500$, $355,300,250,212$ e $180 \mu \mathrm{m})$ usando-se um agitador de peneiras, durante $20 \mathrm{~min}$. $\mathrm{O}$ tamanho das partículas foi avaliado pela quantificação percentual de retenção do pó.

\section{Determinação de perda por dessecação do pó}

Foi baseada no que preconiza a Farmacopéia Brasileira (1988), onde exatamente $3 \mathrm{~g}$ do pó da planta foram transferidos para pesa-filtro. A amostra foi submetida a aquecimento em estufa a $105^{\circ} \mathrm{C}$ durante $2 \mathrm{~h}$, seguida de resfriamento em dessecador e pesagem (Costa, 1982). A operação foi repetida até obtenção de peso constante. Os resultados de três determinações foram avaliados em termos de porcentagem ponderal sobre a quantidade da amostra, utilizando a equação:

$$
\% \text { perda }=\frac{P u-P s}{P a} \times 100
$$

Onde:

$\mathrm{Pa}=$ peso da amostra $(\mathrm{g})$

$\mathrm{Pu}=$ peso do pesa-filtro contendo a amostra antes da dessecação $(\mathrm{g})$

Ps $=$ peso do pesa-filtro contendo a amostra após a dessecação $(\mathrm{g})$

\section{Determinação do teor de cinzas totais do pó}

Foi baseada no que preconiza a Farmacopéia Brasileira (1988), onde exatamente $3 \mathrm{~g}$ do pó, foram transferidos para cadinhos de porcelana previamente calcinados, resfriados e tarados nas condições empregadas durante a análise propriamente dita. As amostras dos pós nos cadinhos foram então carbonizadas em mufla a 450 ${ }^{\circ} \mathrm{C}$ por $2 \mathrm{~h}$. Após resfriamento em dessecador sob vácuo, as mesmas foram pesadas em balança analítica, repetindose o procedimento até a obtenção de peso constante. A percentagem de cinzas foi calculada em relação à droga seca.

\section{Obtenção da tintura}

A extração de ativos da espécie vegetal foi realizada baseada na Farmacopéia Brasileira (1959), empregando-se a maceração por $10 \mathrm{~d}$ em percolador tampado, usando-se a proporção de $200 \mathrm{~g}$ do pó da planta para obtenção de $1000 \mathrm{~mL}$ de tintura. O sistema solvente empregado foi uma mistura hidroalcoólica $70 \%(\mathrm{v} / \mathrm{v})$. Durante todo o processo, o material esteve ao abrigo da luz e em temperatura ambiente.

\section{RESULTADOS E DISCUSSÂO}

\section{Descrição da anatomia foliar}

\section{Anatomia do pecíolo}

A espécie estudada, no plano transversal, apresenta o pecíolo com o formato plano convexo ou levemente côncavo-convexo, em toda sua extensão. Duas projeções laterais são observadas na face adaxial, tornandose mais evidentes em direção à região distal. A epiderme é uniestratificada, contendo tricomas e dotada de cutícula delgada. (Figuras 3, 4 e 5). Os tricomas foram observados por toda a circunferência do pecíolo por Puhl et al., 2007.

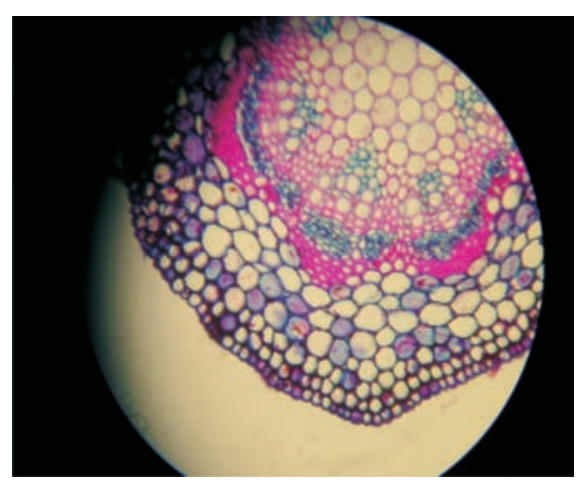

Figura 3. Corte transversal do pecíolo. Epiderme uniestratificada; colênquima angular; parênquima cortical; esclerênquima formando um cilindro contínuo por sobre o floema externo ;xilema; floema interno; parênquima medular.

O colênquima do tipo angular é encontrado subjacente à epiderme, em toda a extensão do pecíolo. $\mathrm{O}$ parênquima cortical apresenta células comparedes delgadas, e pequenos espaços intercelulares (Figuras 3 e 4). Presença de feixes vasculares em toda a extensão do pecíolo com um cilindro de fibras ocorrendo junto ao sistema vascular. No floema foram observados os elementos de transporte e as células companheiras que ocorrem em grupos externos e internos. O xilema está situado entre os elementos do 
floema (Figuras 3 e 6). Entre o esclerênquima e o floema externo há uma faixa de células parenquimáticas (Figura $6)$.

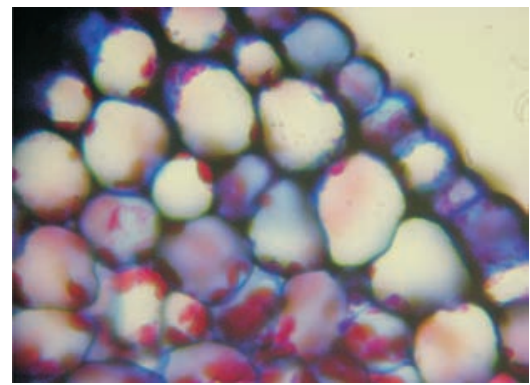

Figura 4. Corte transversal do pecíolo. Detalhe: epiderme; colênquima angular; parênquima cortical.

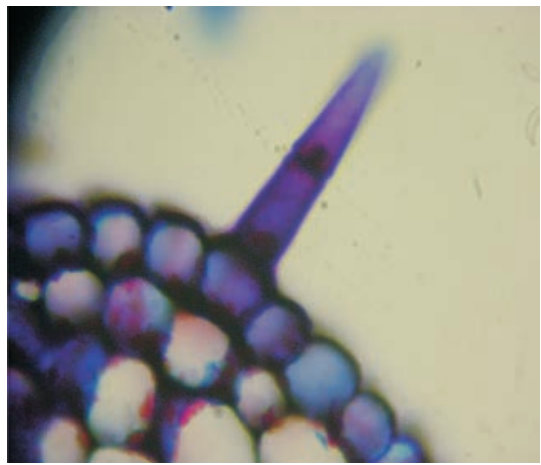

Figura 5. Corte transversal do pecíolo. Detalhe do tricoma e cutícula delgada na epiderme.

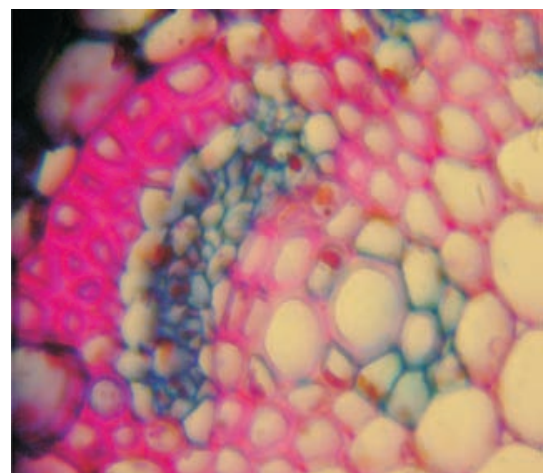

Figura 6. Corte transversal do pecíolo. Detalhe do sistema vascular e esclerênquima; floema externo; xilema; floema interno; esclerênquima; células parenquimáticas.

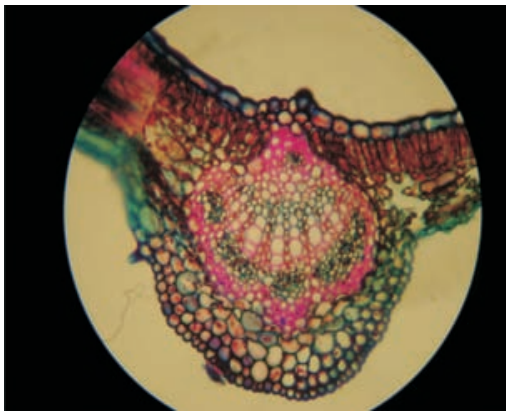

Figura 7. Aspecto geral da região mediana da folha em corte transversal. Nervura principal e bordos laterais em cuja epiderme inferior encontram-se os tricomas secretores e tectores.

\section{Anatomia do limbo}

Os folíolos são hipoestomáticos e dorsiventrais e o mesofilo é heterogêneo, formado por dois estratos de parênquima paliçádico abaixo da epiderme adaxial e por seis estratos de parênquima lacunoso abaixo da epiderme abaxial. O bordo apresenta-se encurvado em direção à face abaxial e é ocupado por elementos de parênquima clorofiliano (Figuras 8, 9 e 10).

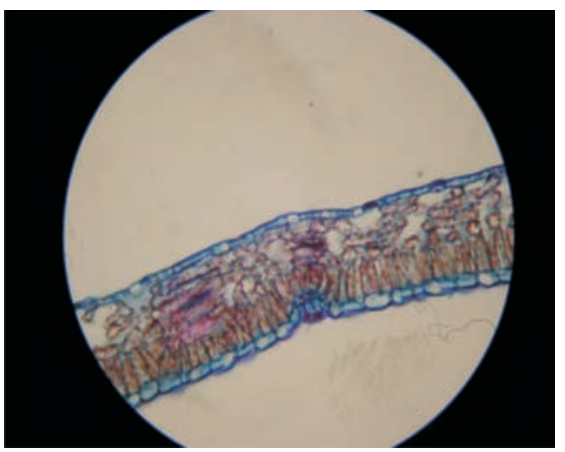

Figura 8. Corte transversal da região basal do limbo foliar. Tricoma secretor; estômatos; nervura lateral; sistema vascular e câmara subestomática.

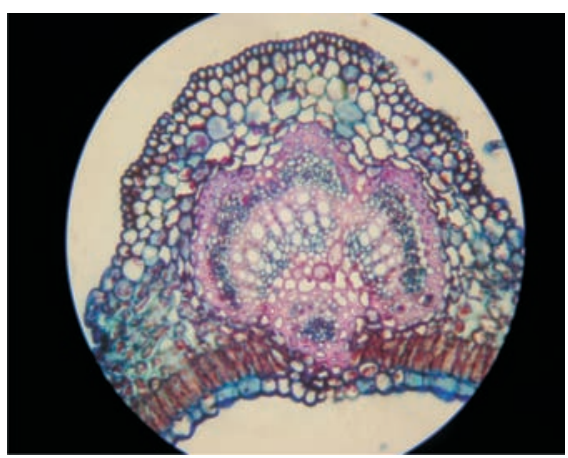

Figura 9. Corte transversal do limbo da região basal. Epiderme superior; epiderme inferior; colênquima angular; parênquima fundamental; esclerênquima; floema; xilema; parênquima paliçádico e cutícula.

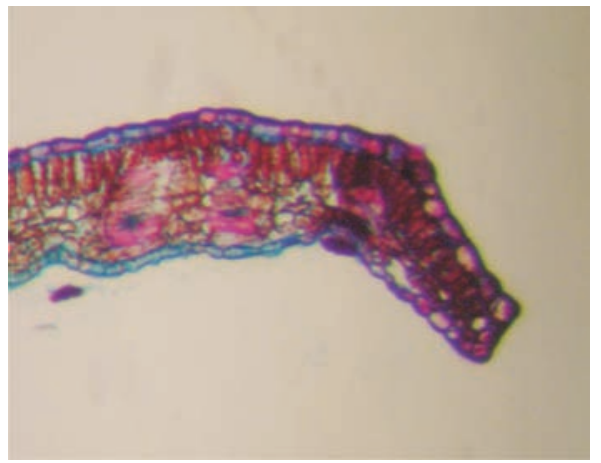

Figura 10. Corte transversal do bordo lateral da região mediana da folha, evidenciando as nervuras laterais presentes ao nível do parênquima lacunoso. 


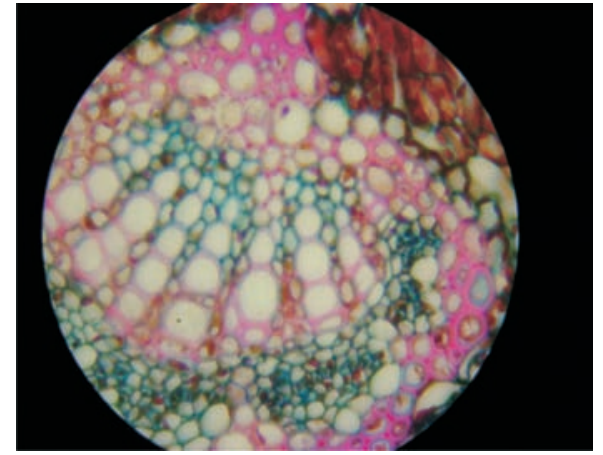

Figura 11. Detalhe da nervura principal enfocando a diferença entre xilema e floema. Aspecto citológico das células xilemáticas e floemáticas. Os elementos radiais de vasos do xilema estão com suas paredes espessadas e esclerificadas, e são separados entre si por parenquimáticas, enquanto que os elementos de tubos crivados do floema destacam-se com a presença das placas crivadas e suas células companheiras. Ambos têm paredes delgadas.

A nervura principal contém feixe de xilema radial, sendo que entre os vasos xilemáticos encontram-se células parenquimáticas e o floema se distribui em forma de arco voltado para a face abaxial da folha e em grupo de poucas células voltadas para a face adaxial (Figura 11). Em corte transversal, o folíolo, apresenta-se constituído por uma nervura principal e bordos laterais, revestido por uma epiderme uniestratificada com cutícula delgada. Pulh et al. (2007), observaram que na epiderme de Arrabidaea chica (H\&B) Verlt., Bignoniaceae, as células da face adaxial são mais volumosas que as da face oposta e que a cutícula é ornamentada por estrias, o que não foi observado no presente estudo. Na epiderme inferior, encontram-se tricomas simples tectores e tricomas secretores (Figura 7), além de estômatos (Figura 8). Segundo Oliveira et al. (1998), tricomas tectores de formatos diversos foram descritos para espécies de Bignoniaceae. Pulh et al. (2007), referem que os estômatos presentes em A. chica são do tipo anisocíticos e presentes apenas na face abaxial dos folíolos.

No terço basal da lâmina foliar, o sistema vascular predomina na nervura principal e está formado por feixes colaterais fechados com diâmetro maior do que nas nervuras laterais. Em torno dos tecidos condutores, encontra-se uma bainha de esclerênquima, caracterizando um feixe fechado. Há estômatos presentes na epiderme inferior, estando as câmaras subestomáticas bem diferenciadas no parênquima lacunoso (Figura 7).

Subjacente às epidermes, o colênquima angular está formado por dois estratos celulares que acompanham toda a base da nervura, enquanto que na face superior, apenas duas faixas de dez células colenquimáticas estão presentes. O parênquima paliçádico penetra na face superior da nervura. As células epidérmicas têm a forma esférica na face inferior e retangular na face superior (Figura 9).

Nos bordos laterais, encontram-se as nervuras laterais ao nível do parênquima lacunoso (Figura 10) e nestas, há feixes colaterais fechados, constituídos por xilema organizado na forma radial e floema constituído por agrupamento de elementos de tubos crivados e células companheiras. No pólo inferior do feixe, a bainha esclerenquimática encontra-se como calota de fibras e no pólo superior, as fibras estão em feixes (oito fibras) estreitando-se em direção à face adaxial, sendo que os espaços existentes entre os elementos vasculares xilemáticos e os floemáticos. Na porção superior de cada nervura lateral encontram-se quatro células de colênquima angular subepidérmico, cujas paredes são mais espessadas nos ângulos (Figura 12). Na porção inferior da nervura principal, o colênquima angular é biestratificado, situado acima da epiderme inferior e acima dele há três estratos de células parenquimáticas, sobre os quais, encontram-se as calotas de fibras da bainha esclerenquimática (Figura 13). Puhl et al. (2007), citam que além da presença na nervura principal o colênquima angular é encontrado circundando o pecíolo. Na região apical do mesófilo observam-se os elementos vasculares (Figura 14).

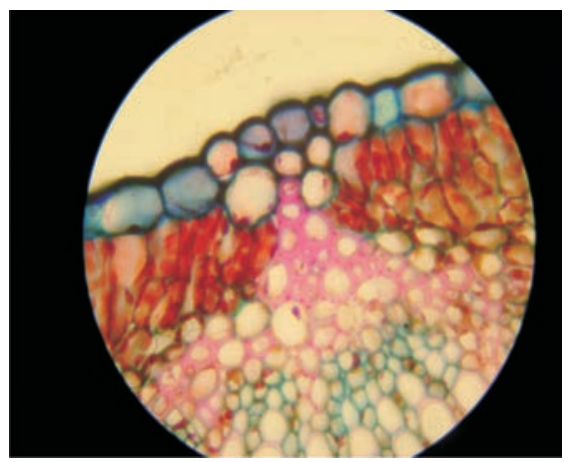

Figura 12. Detalhe de parte superior da nervura lateral na região mediana da folha em corte transversal. Aspecto apresentado pelas células do colênquima angular subepidermico, cujas paredes são mais espessadas nos ângulos, e do esclerênquima representado pelas fibras de paredes espessadas e esclerificadas e das células parenquimáticas e estruturas secretoras constituintes do xilema.

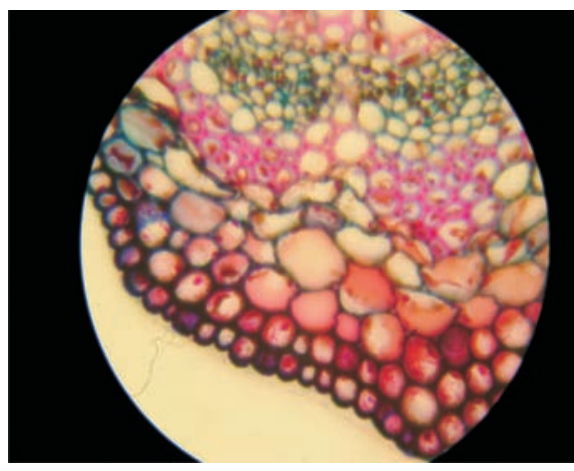

Figura 13. Detalhe da parte inferior da nervura principal da região mediana da folha em corte transversal. Acima da epiderme inferior, identifica-se um colênquima anelar uniestratificado e acima dele há quatro estratos de células parenquimáticas, sobre os quais, evidencia-se a calota inferior de fibras da bainha esclerenquimática. 


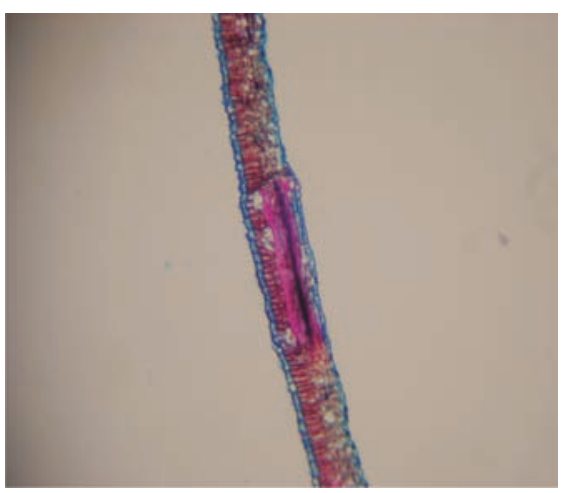

Figura 14. Mesofilo da região apical. Elementos vasculares dispostos em corte longitudinal.

$\mathrm{Na}$ região apical, o limbo foliar apresenta o mesmo padrão anatômico da região basal, tanto na região da nervura principal, quanto nos bordos laterais (Figuras 12 e 13$)$.

\section{Determinação da distribuição granulométrica do pó de Arrabidaea chica}

A determinação da distribuição granulométrica, além de contribuir como análise de caracterização da matéria prima vegetal, demonstrou especificações de acordo com a Farmacopéia Brasileira (1988), onde se constatou que o pó é classificado como sendo grosso, já que menos de $40 \%$ das partículas do pó passou pelo tamis com abertura nominal de malha de $355 \mu \mathrm{m}$ conforme Figura 15.

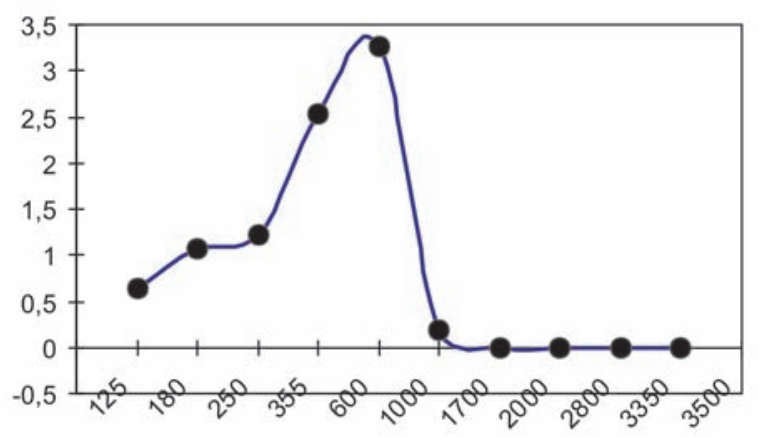

Figura 15. Determinação da distribuição granulométrica do pó de Arrabidaea chica (Humb. \& Bonpl) B. Verlt.

É importante que a matéria prima vegetal esteja suficientemente pulverizada para que se consiga um rendimento ótimo no processo de extração dos constituintes químicos de interesse farmacêutico. A granulometria da matéria prima vegetal é o parâmetro que determina a superfície de contato disponível para a interação com o solvente utilizado na obtenção de preparações intermediárias líquidas, como tintura e extratos.

O processo de pulverização da matéria prima vegetal constitui uma etapa crítica na produção de medicamentos fitoterápicos, uma vez que o produto pulverizado representa na maioria das vezes o insumo indispensável para obtenção de preparações intermediárias, desse modo, o controle da tenuidade de pós é uma etapa óbvia no processo de produção (Silva Júnior, 2006).

\section{Determinação de perda por dessecação e do teor de cinzas totais de Arrabidaea chica}

A perda por dessecação do pó da planta apresentou um coeficiente de variação de $9,18 \%$, e o resultado encontrado na determinação do teor de cinzas totais foi de 6,07 , conforme tabela 1 .

Tabela 1. Perda por dessecação e do teor de cinzas totais do pó da matéria prima vegetal.

\begin{tabular}{clc}
\hline Testes & y & Determinações (\%) \\
\hline Perda por dessecação & 3 & $9,18 \pm 0,118$ \\
Teor de cinzas totais & 3 & $6,07 \pm 0,463$ \\
\hline
\end{tabular}

A determinação do teor de água residual presente nas drogas vegetais constitui um índice da qualidade de sua preparação e da garantia de sua conservação (Costa, 1982; Silva Júnior, 2006). A perda por dessecação do pó da planta, indicativo do teor de material volátil do vegetal e, indiretamente da umidade residual, apresentou um coeficiente de variação de $9,18 \%$, conforme Tabela 1 , o qual se encontra dentro do limite estabelecido pelas diferentes farmacopéias que é de $8 \%$ a $14 \%$, indicando uma boa conservação e uma secagem eficiente da matéria prima vegetal. Esta determinação é importante para o controle de qualidade microbiológico, pois um excesso de água na droga vegetal favorece o crescimento de fungos e bactérias, podendo também levar à hidrólise de seus constituintes (Sharapin, 2000).

A determinação de cinzas totais do pó da planta permite a quantificação do resíduo não volátil inorgânico presente nas drogas vegetais como integrante natural destas, sendo constituído, em particular, por carbonatos, cloretos e diversos tipos de óxidos (Costa, 1982), podendo servir como método para avaliar a pureza do material, detectando a presença excessiva de substâncias aderentes (Silva Júnior, 2006). O resultado encontrado na determinação do teor de cinzas totais que foi de 6,07, conforme Tabela I, não foi encontrado nas literaturas pesquisadas, porém, sabe-se que inúmeros fatores podem alterar esse teor, tais como aqueles relacionados aos procedimentos de coleta, secagem e variações climáticas, ou mesmo devido às diferenças em termos de localização geográfica dos materiais analisados.

\section{Abordagem fitoquímica}

A abordagem fitoquímica da tintura indicou a presença de classes químicas tais como: açúcar redutor, 
alcaloides, antocianidinas, antocianinas, antraquinonas, esteroides, triterpenoides, fenóis, flavanonóis, flavanóis, flavanonas, saponinas e taninos catéquicos (Tabela 2), que corroboram com os resultados obtidos por Barbosa \& Quinard (1998). O resultado positivo para alcaloides pode ser resultado de reação cruzada do reativo de Dragendorff com quinonas. A tentativa de preparar uma fração alcaloídica a partir da droga, por partição ácidoácido, não forneceu resultados positivos para tal classe de metabólitos.

Tabela 2. Prospecção química em tintura da Arrabidaea chica (Humb. \& Bonpl) B. Verlt.

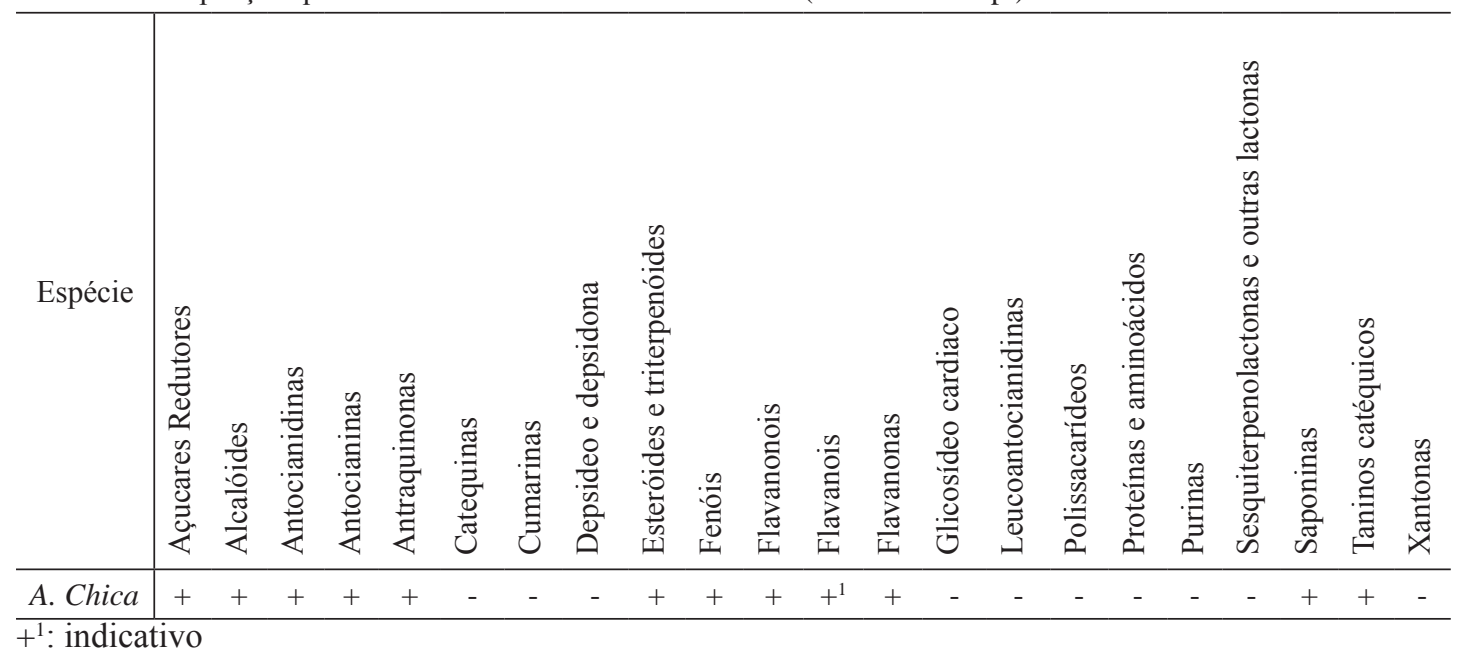

\section{CONCLUSÃO}

As análises realizadas neste trabalho para a caracterização da Arrabidaea chica (H\&B) Verlot., Bignoniaceae, demonstraram que os procedimentos adotados desde a coleta, identificação, secagem e pulverização do material estão dentro das especificações farmacopéicas, pois observou-se que o pó da matéria vegetal apresentou umidade dentro do limite estabelecido pelas farmacopéias, o que demonstra que a obtenção e secagem do material foi eficiente, indicando uma boa conservação e estabilidade do material vegetal.

Com o desenvolvimento deste trabalho foi possível a obtenção de parâmetros para o controle de qualidade, que visam contribuir para a segurança da qualidade de matérias primas obtidas da Arrabidaea chica (Humb. \& Bonpl.) B. Verlt. como ponto de partida para estudos posteriores.

\section{REFERÊNCIAS}

Amoroso MCM, Gely 1988. O uso de plantas medicinais por caboclos do Baixo Amazonas. Barcarena: Museu Paraense Emilio Goeldi.

Anvisa 2004. RDC no 48, 16 de março de 2004. Dispõe sobre o registro de medicamentos fitoterápicos

Barbosa WLR, Quignard E 1997-1998. Projeto integradoConselho Nacional de Desenvolvimento Cientifico e Tecnológico-Relatório final de atividades. Belém-PA.

Corrêa MP 1984. Dicionário das plantas úteis do Brasil e das exóticas cultivadas. Rio de Janeiro: Ministério da Agricultura.

Costa AF 1982. Farmacognosia. Lisboa: Calouste Gulbenkian.
Estrela E 1995. Tratado de cooperacion amazonica-secretaria protempore, plantas medicinales amazonicas: realidad y perspectivas. Lima: TCA.

Farmacopéia Brasileira 1988. $4^{\mathrm{a}}$ ed. São Paulo: Atheneu.

Farmacopéia Brasileira 1959. $2^{\mathrm{a}}$ ed. São Paulo: Gráfica Siqueira.

Grenard P 1987. Pharmacopees traditionelles em Guyana. Paris: L'orstom.

Ko RJ 1999. Causes, epidemiology, and clinical evaluation of suspected herbal poisoning. Clin Toxicol 37: 697-708.

Oliveira F, Akisue K, Akisue MK 1998. Farmacognosia. São Paulo: Atheneu.

Pauletti PM, Bolzani VS, Yung MCM 2003. Constituintes químicos da Arrabidaea (Bignoniaceae). Quim Nova 26: 641-643.

Puhl MCMN, Milaneze-Gutierre MA, Nakamura CV, Cortez DAG 2007. Lat Am J Pharm 26: 224-229.

Sharapin N 2000. Fundamentos de tecnologia de produtos fitoterápicos. Santafé de Bogotá: Convenio Andrés Bello.

Silva Júnior JOC 2006. Obtenção e avaliação de forma farmacêutica semi-sólida fitoterápica contendo extrato seco por nebulização de Simphytum officinale $L$. (confrei). São Paulo, Tese de doutorado, Programa de Pósgraduação em Fármacos e Medicamentos, Universidade de São Paulo.

Takemura OS 1995. A flavone form leaves of Arrabidaea chica f. cuprea. Phitochemistry 38: 1299-1300.

Turolla MSR, Nascimento E 2006. Informações toxicológicas de alguns fitoterápicos utilizados no Brasil. Braz J Pharm Sci 42: 125-131.

Tyler VE 1996. Natural products and medicine: an overview. In: Balick MJ, Elisabetsky E, Laird SA. (eds.). Medicinal resources of the tropical forest, biodiversity and its importance to human health. New York: Columbia University Press, p. 3-10. 